\title{
Identifikasi Potensi Wilayah Perikanan di Kecamatan Air Rami Kabupaten Mukomuko Provinsi Bengkulu
}

\author{
[Identification of Potentials of Fisheries Areas in Rami Water District \\ Mukomuko District, Bengkulu Province]
}

\section{Dwi Anggi Saputra, Yenni Nuraini, Tatty Yuniarti}

Program Studi Penyuluhan Perikanan Politeknik Ahli Usaha Perikanan

Jalan Cikaret Nomor 2 Bogor 16132, Jawa Barat

\begin{abstract}
Abstrak
Salah satu metode untuk mengetahui identifikasi potensi wilayah perikanan di Kecamatan Air Rami Kabupaten Mukomuko Provinsi Bengkulu adalah mempelajari dan mengidentifikasi potensi wilayah perikanan. Tujuan penelitian adalah mengidentifikasi potensi wilayah perikanan berupa sumber daya alam, sumber daya manusia, sistem produksi perikanan, dan kegiatan penyuluhan perikanan. Metode penelitian melalui wawancara dengan masyarakat dan menggunakan kuesioner. Data primer didapat dari pengamatan langsung terhadap nelayan, data sekunder diproses melalui penelitian dari berbagai sumber. Penelitian dilaksanakan pada tanggal 1 Oktober sampai 30 Oktober 2019. Hasil penelitian yaitu luas wilayah Kecamatan Air Rami $\pm 99,20$ $\mathrm{km}^{2}$ serta jumlah RTP sebanyak 120 RTP dibidang penangkapan. Kondisi wilayah Kecamatan Air Rami adalah salah satu Kecamatan yang memiliki potensi cukup baik dalam bidang perikanan di Kabupaten Mukomuko. Sistem produksi penangkapan ikan di Kecamatan Air Rami menggunakan jenis alat tangkap left net, fish net, pancing/tonda, dan pukat tradisional. Kegiatan penyuluhan perikanan berjalan berdasarkan aspirasi dari masyarakat, peran penyuluh sangat penting bagi masyarakat guna meningkatkan kelompok perikanan. Wilayah tersebut berpotensi karena kondisi sumber daya alam dan sumber daya manusia yang memadai untuk kegiatan perikanan.
\end{abstract}

Kata Kunci: nelayan; penangkapan; penyuluhan; perikanan; RTP

\section{Abstract}

One method for identifying the potential identification of fishery areas in the district of Air Rami Mukomuko District of Bengkulu Province was to study and identify the potential of fishery areas. The objective of research was to identify the potential of fishery areas in the form of natural resources, human resources, fishery production systems, and fisheries outreach activities. The Methods were done through interviews with the community and using questionnaires. Primary data was obtained from direct observation of fishermen, secondary data was processed through research from various sources. The study was conducted on 1st October until 30th October 2019. The results of the research were the area of Kecamatan Air Rami $\pm 99.20 \mathrm{~km}^{2}$ as well as the number of RTP of 120 RTP the field of arrest. Condition of the area of Air Rami Sub-district is one of the subdistrict that has good enough potentials in the field of fisheries in Mukomuko district. The fish production system in Kecamatan Air Rami used the kind of Left Net capture tool, Net fish, fishing rod/Tonda, and traditional Pukat. Fishery outreach activities run based on the aspirations of the community, extension roles were very important for the community to improve the fishery group. The area was potentially due to adequate natural resources and human resources conditions.

Keywords: extension; fisheries; fisherman; production; RTP 


\section{Penulis Korespondensi}

Dwi Anggi Saputra | anggidwisaputra52@gmail.com

\section{PENDAHULUAN}

Kecamatan Air Rami termasuk dalam Kabupaten Mukomuko, terletak di sebelah utara Provinsi Bengkulu. Kecamatan Air Rami dibentuk berdasarkan Perda No 8 Tahun 2005. Kecamatan Air Rami memiliki luas wilayah 99,20 $\mathrm{km}^{2}$, dengan ibukota Kecamatan Arga Jaya. Batas-batas wilayah kecamatan Air Rami adalah sebelah utara Kecamatan Ipuh dan Kecamatan Malin Deman, sebelah selatan Kabupaten Bengkulu Utara, sebelah timur Provinsi Jambi, sebelah barat Samudera Hindia. Kecamatan Air Rami merupakan wilayah pedesaan terdiri dari 12 desa definitif. Secara geografis, hampir semua desa terletak di daerah bukan pantai, kecuali desa Air Rami yang berbatasan dengan Samudera Hindia (Badan Pusat Statistik 2018).

Penyuluhan perikanan adalah salah satu kegiatan yang dapat memfasilitasi dan mengkomunikasikan teknologi perikanan dan informasi terbaru bidang perikanan sehingga dapat membantu mengoptimalkan potensi perikanan (Mahfrudin, Yuniarti, dan Ruchimat 2020). Pendekatan potensi sumberdaya perikanan pesisir secara terpadu terhadap aspek pengelolaan sumberdaya perikanan yang meliputi: aspek ekologi, aspek ekonomi, aspek teknologi, aspek sosial kultural masyarakat, dan aspek ekternal belum tersusun dengan baik, sehingga kadang terjadi tumpang tindih pengelolaan sumberdaya antara beberapa sektor pembangunan (Kusnandar dan Mulyani 2015). Pengoptimalan potensi sumber daya perikanan dilakukan identifikasi potensi wilayah sehingga dapat diketahui data aktual dan potensial sehingga dapat membantu merumuskan aksi penyuluhan yang sesuai dengan kebutuhan di Kecamatan Air Rami, Kabupaten Mukomuko Provinsi Bengkulu.

Potensi sumberdaya perikanan meliputi sumberdaya manusia, sumberdaya alam serta kegiatan perekonomian masyarakat perikanan di suatu wilayah. Hasil identifikasi kajian potensi perikanan dapat bermanfaat untuk meningkatkan perekonomian masyarakat sekitar wilayah perikanan dengan menjaga kelestarian lingkungan perikanan secara terus menerus (Hendrik 2010). Tujuan penelitian mengidentifikasi potensi wilayah perikanan berupa SDA, SDM, dan mengidentifikasi sistem produksi perikanan, mengidentifikasi kegiatan penyuluhan. 
Tabel 1. Jenis Data

\begin{tabular}{|c|c|c|}
\hline Jenis Data & Sumber & Cara Pengumpulan Data \\
\hline $\begin{array}{l}\text { Kondisi Umum } \\
\text { Sumberdaya } \\
\text { Alam }\end{array}$ & $\begin{array}{l}\text { Data sekunder (Dinas } \\
\text { perikanan) }\end{array}$ & Keadaan lokasi kecamatan Air Rami \\
\hline $\begin{array}{l}\text { Kondisi Umum } \\
\text { Usaha Perikanan }\end{array}$ & $\begin{array}{l}\text { Data sekunder (Dinas } \\
\text { Perikanan) } \\
\text { Data Primer (Usaha } \\
\text { penangkapan) }\end{array}$ & $\begin{array}{l}\text { Pengambilan data di } 20 \% \text { desa } \\
\text { Kecamatan Air Rami Kabupaten } \\
\text { Mukomuko yaitu Desa Air Rami dan } \\
\text { Desa Talang Rio }\end{array}$ \\
\hline $\begin{array}{l}\text { Usaha } \\
\text { Penangkapan } \\
\text { Ikan }\end{array}$ & $\begin{array}{l}\text { Data primer } \\
\text { (Nelayan,Staf } \\
\text { Pelabuhan) }\end{array}$ & $\begin{array}{l}2 \text { jenis penangkapan ikan Desa } \\
\text { Sampel dengan jumlah nelayan } \\
\text { sebanyak } 25 \text { orang }\end{array}$ \\
\hline $\begin{array}{l}\text { Kondisi Ekonomi } \\
\text { Pelaku Usaha }\end{array}$ & $\begin{array}{l}\text { Data Primer (Pelaku } \\
\text { Utama,Pelaku Usaha) }\end{array}$ & $\begin{array}{l}\text { Kondisi ekonomi dari pelaku usaha } \\
\text { pengolahan, dan penangkapan di Desa } \\
\text { sampel }\end{array}$ \\
\hline $\begin{array}{l}\text { Keragaan } \\
\text { Penyuluh }\end{array}$ & $\begin{array}{l}\text { Data Primer (Penyuluh } \\
\text { Perikanan) }\end{array}$ & $\begin{array}{l}1 \text { Penyuluh Perikanan bantu yang } \\
\text { terdapat di kecamatan Air Rami }\end{array}$ \\
\hline
\end{tabular}

\section{BAHAN DAN METODE}

Penelitian dilaksanakan pada tanggal 1 Oktober sampai dengan 30 Oktober 2019 yang bertempat di Kecamatan Air Rami Kabupaten Mukomuko Provinsi Bengkulu. Alat yang digunakan untuk mengumpulkan data dalam kegiatan penelitian adalah kuesioner. Teknik pengambilan sampel digunakan adalah stratified random sampling (acak berlapis). Jenis data digunakan yaitu data primer dan data sekunder. Metode yang digunakan pada penelitian ini adalah observasi dan studi literatur. Data yang diperoleh disajikan menggunakan analisa statistik sederhana dan ditampilkan dalam tabulasi dan grafik. Berikut adalah jenis data dan sumber perolehan data.
Jumlah sampel responden dilakukan tergantung dari jumlah populasi. Jumlah populasi $<100$ penentuan sampel dilakukan dengan teknik sensus, yaitu pengambilan data dari semua elemen/anggota dari suatu populasi. Kecamatan Air Rami jumlah populasi $>100$, penentuan sampel dilakukan dengan menggunakan teknik penentuan sampel menurut slovin, rumus slovin yang digunakan dalam penentuan jumlah sampel sebagai berikut:

$$
\begin{gathered}
n=\frac{N}{1+N(e)^{2}}=\frac{120}{1+120(20 \%)^{2}} \\
n=\frac{120}{4,8}=25 \text { Responden }
\end{gathered}
$$

Keterangan :

$\mathrm{n}$ : ukuran sampel

$\mathrm{N}$ : ukuran populasi

$\mathrm{e}$ : persen kelonggaran ketidak pastian karena kesalahan 


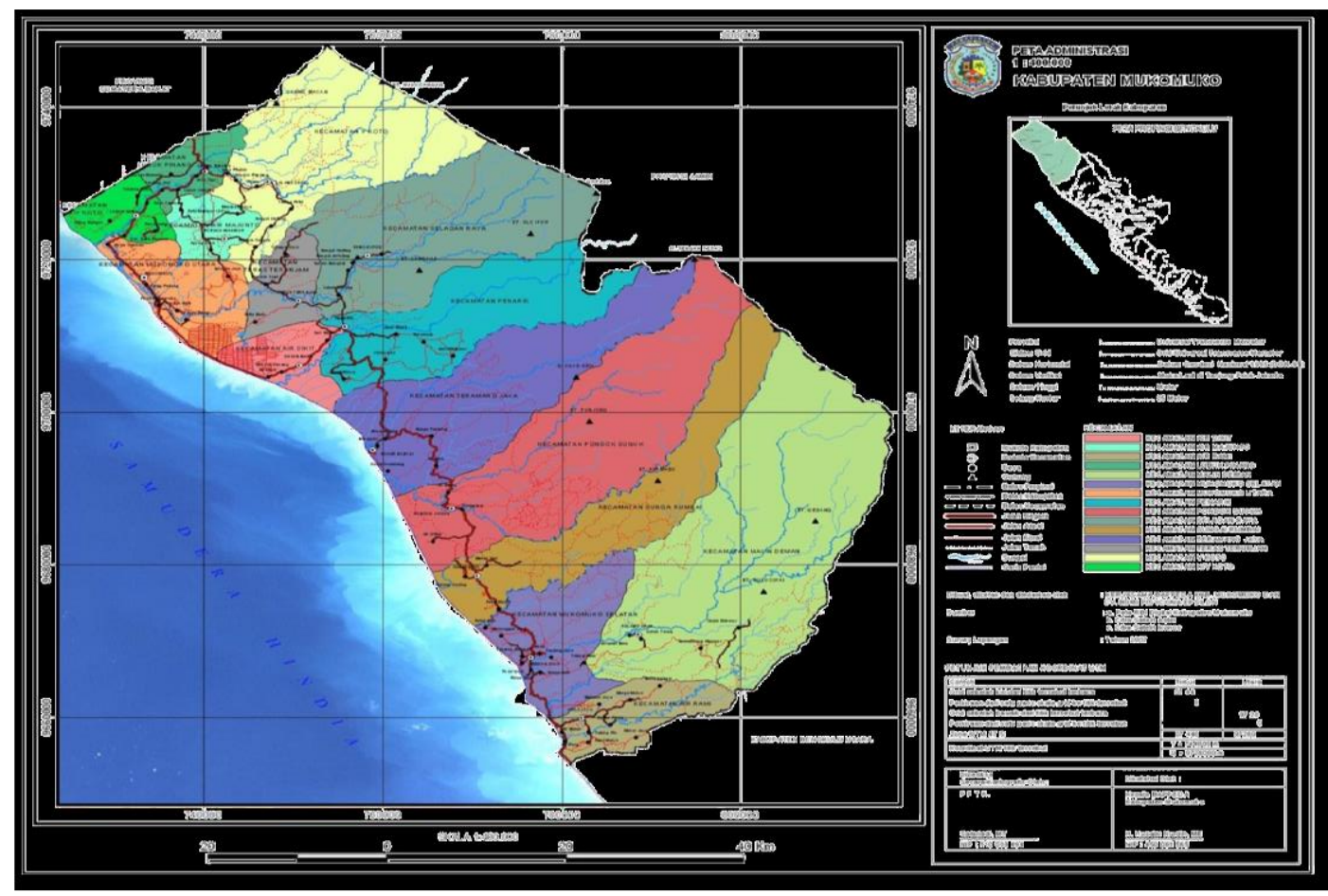

Gambar 1. Peta Kabupaten Mukomuko Sumber : BPS Kabupaten Mukomuko 2019

Penentuan jumlah sample kelompok akan di ambil dari $20 \%$ desa yang akan di identifikasi baik pembenihan, budidaya, pengolahan, dan penangkapan. Desa Air Rami memiliki populasi sebanyak 100 RTP dengan responden 21. Desa Talang Rio memiliki populasi sebanyak 20 RTP dengan responden 4.

\section{HASIL DAN PEMBAHASAN}

\section{Hasil}

Kondisi Wilayah Kabupaten Mukomuko

Kabupaten Mukomuko terletak di sebelah paling utara Provinsi Bengkulu. Luas wilayah Kabupaten Mukomuko mencapai sekitar 4.146,52 kilometer persegi. Wilayah Kabupaten Mukomuko terbentang dari Kabupaten Pesisir Selatan (Provinsi Sumatera Barat) sampai Kabupaten Bengkulu Utara dan jaraknya kurang lebih 250 kilometer. Secara astronomis, Kabupaten Mukomuko terletak di antara $101^{\circ} 01^{\prime} 36^{\prime \prime}$ - $101^{\circ} 51^{\prime} 08^{\prime \prime}$ BT dan $02^{\circ} 16^{\prime} 06^{\prime \prime}-03^{\circ}$ 07' 08" LS.

Batas administratif Kabupaten Mukomuko sebagai berikut :

- Sebelah Utara : Kabupaten Pesisir Selatan, Sumatera Barat

- Sebelah Selatan : Kabupaten Bengkulu Utara

- Sebelah Barat : Samudera Hindia

- Sebelah Timur : Kabupaten Kerinci dan Kabupaten Merangin 
Musim yang terjadi di kabupaten Mukomuko sebagaimana wilayah lainnya di Indonesia dikenal dua musim, yaitu musim hujan (Oktober-Maret) dan musim kemarau (April-September). Sementara pada bulan Februari-maret dan AgustusSeptember merupakan masa peralihan/pancaroba (Badan Pusat Statistik 2018).

Kecamatan Air Rami adalah salah satu wilayah yang berada di bagian selatan Kabupaten Mukomuko. Kecamatan Air Rami memiliki luas wilayah $\pm 99,20 \mathrm{~km}^{2}$, dengan ibukota kecamatan di Desa Arga Jaya. Jarak dari ibukota Kabupaten Mukomuko \pm 120 km melalui jalur Lintas Barat Sumatera. Wilayah Kecamatan Air Rami terbagi menjadi 12 desa. Diantaranya yaitu Air rami, Rami Mulya, Mekar Jaya, Dusun Pulau, Talang Rio, Arga Jaya, Makmur Jaya, Marga Mulya, Bukit Harapan, Tirta Kencana, Bukit Mulya dan Cinta Asih.
Kecamatan Air Rami berbatasan langsung dengan wilayah - wilayah sebagai berikut :

- Utara : berbatasan dengan Kecamatan Ipuh dan Kecamatan Malin Deman

- Selatan : berbatasan dengan Kabupaten Bengkulu Utara

- Barat : berbatasan dengan Samudera Hindia

- Timur : berbatasan dengan Provinsi Jambi

Kondisi Potensi Sumber Daya Manusia Sumarsono (2003) menjelaskan Sumber Daya Manusia menyangkut manusia yang mampu bekerja untuk memberikan jasa atau usaha kerja tersebut. Sumber daya manusia di Kecamatan Air Rami tahun 2019 mempunyai penduduk sebesar 11.327 jiwa, jumlah penduduk laki-laki sebanyak

Tabel 2. Penduduk Kecamatan Air Rami Menurut Jenis Kelamin

\begin{tabular}{lccccc}
\hline No. & Tahun & Laki-laki & Perempuan & Jumlah & Rasio Jenis Kelamin \\
\hline 1. & 2013 & 5.448 & 5.010 & 10.458 & 108,74 \\
2. & 2014 & 5.568 & 5.125 & 10.693 & 108,64 \\
3. & 2015 & 5.640 & 5.193 & 10.833 & 108,61 \\
4. & 2016 & 5.706 & 5.262 & 10.968 & 108,44 \\
5. & 2017 & 5.774 & 5.321 & 10.095 & 108,51 \\
6. & 2018 & 5.838 & 5.375 & 11.213 & 108,61 \\
7. & $\mathbf{2 0 1 9}$ & $\mathbf{5 . 8 9 0}$ & $\mathbf{5 . 4 3 7}$ & $\mathbf{1 1 . 3 2 7}$ & $\mathbf{1 0 8 , 3 3}$ \\
\hline
\end{tabular}

Sumber: (Badan Pusat Statistik 2018) 
5.890 jiwa dan perempuan sejumlah 5.437 jiwa.

Usaha perikanan di Kecamatan Air Rami mayoritas pelaku usaha dalam sektor penangkapan. Kondisi umum usaha perikanan meliputi jumlah pelaku utama atau pelaku usaha yang ada di kecamatan Air Rami yaitu perikanan tangkap sebanyak 120 RTP, yang bersumber dari data sekunder yang tercatat di Dinas Kelautan dan Perikanan Kabupaten Mukomuko 2019. Kecamatan Air Rami memiliki 12 kelompok perikanan yang terdiri dari kelompok penangkapan ikan. Kelas kelompok di Kecamatan Air rami ini rata-rata masih tergolong kelas pemula. Kelompok belum memenuhi syarat untuk naik kelas berikutnya, terutama dalam menjalankan buku administrasi kelompok. Data kelompok perikanan di Kecamatan Air Rami disajikan pada Tabel 2.

\section{Sistem Produksi Perikanan Tangkap Undang-Undang Republik} Indonesia (UU) No.45 Tahun 2009 tentang perikanan. Sistem produksi perikanan di Kecamatan Air Rami paling mendominasi adalah perikanan tangkapnya dilihat jumlah RTP mencapai 120 RTP yang tersebar di dua desa sampel. Nelayan menangkap ikan

Tabel 2. Data Kelompok Perikanan di Kecamatan Air Rami

\begin{tabular}{lllllll}
\hline Desa & Kelompok & Ketua & $\begin{array}{c}\text { Jumlah } \\
\text { Anggota }\end{array}$ & $\begin{array}{c}\text { Tahun } \\
\text { Berdiri }\end{array}$ & $\begin{array}{c}\text { Kelas } \\
\text { Kelompo } \\
\text { k }\end{array}$ & $\begin{array}{c}\text { Bidang } \\
\text { Usaha } \\
\text { Perikanan }\end{array}$ \\
\hline Air Rami & Dober & $\begin{array}{l}\text { Hasan } \\
\text { Banboy }\end{array}$ & 10 & 2012 & Pemula & Penangkapan \\
Talang Rio & Usaha Makmur & Asri & 10 & 2015 & Pemula & Penangkapan \\
Air Rami & Embun Pagi & Daman Huri & 10 & 2012 & Pemula & Penangkapan \\
Talang Rio & Talang Rio & Koman & 10 & 2015 & Pemula & Penangkapan \\
Air Rami & Harapan Jaya & Sambari & 10 & 2012 & Pemula & Penangkapan \\
Air Rami & Lautan Berlian & Sapar & 10 & 2015 & Pemula & Penangkapan \\
Air Rami & Bintang Laut & Mardinal & 10 & 2016 & Pemula & Penangkapan \\
Air Rami & Camar Laut & Zuliadi & 10 & 2016 & Pemula & Penangkapan \\
Air Rami & Murni Laut & Abdul & 10 & 2015 & Pemula & Penangkapan \\
Air Rami & Tuna Jaya & Rustam & 10 & 2014 & Pemula & Penangkapan \\
Air Rami & Kuda Laut & A.Darman & 10 & 2015 & Pemula & Penangkapan \\
Air Rami & Putera Malayu & Aripal & 10 & 2015 & Pemula & Penangkapan \\
\hline Jumlah anggota kelompok & & $\mathbf{1 2 0}$ RTP & & & \\
\hline
\end{tabular}

Sumber : Data Penyuluh Perikanan Kecamatan Air Rami 2019 


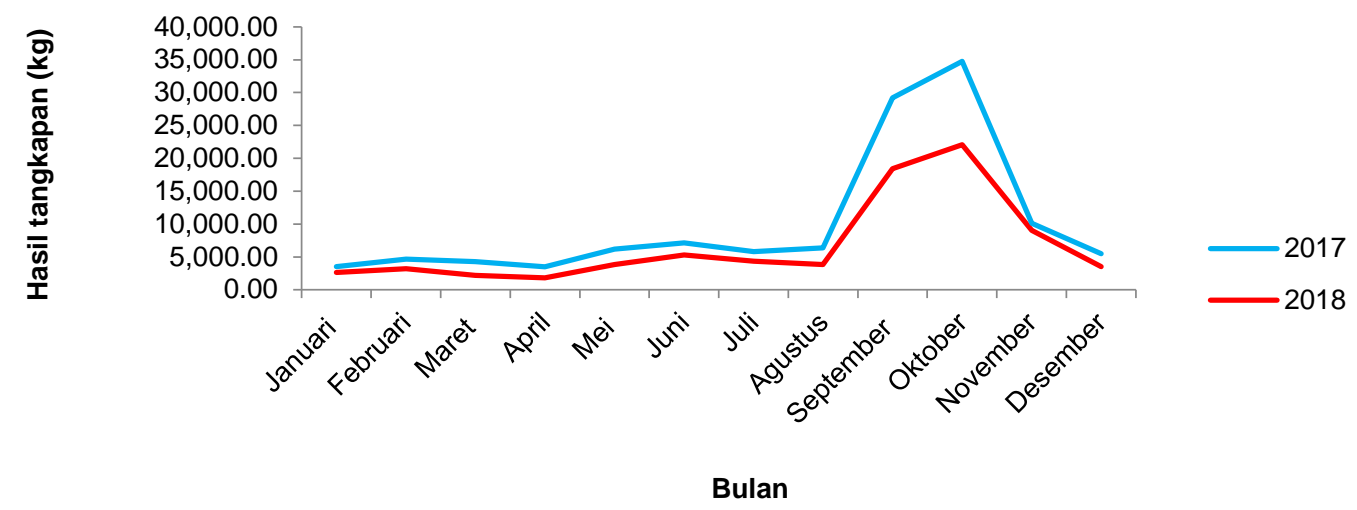

Gambar 2. Gambar Hasil Tangkapan lkan (kg) Sumber : Data sekunder (Badan Pusat Statistik 2018)

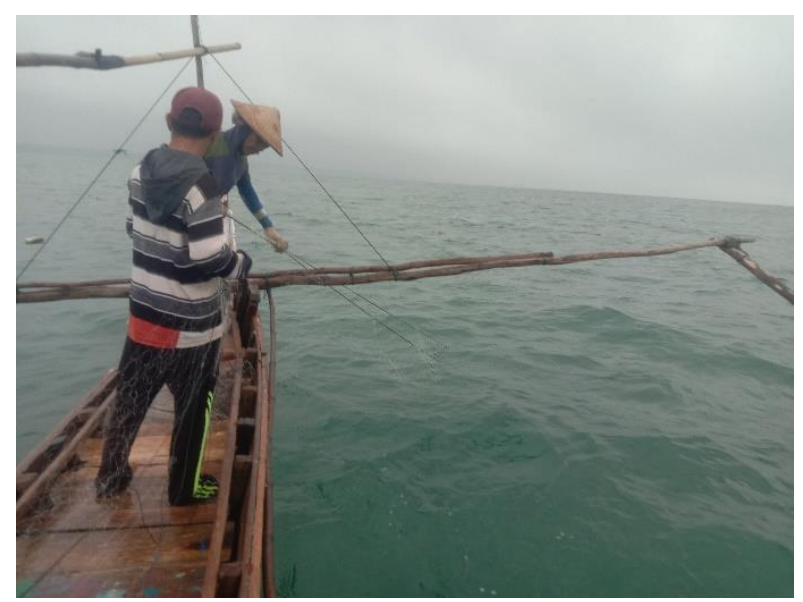

Gambar 3. Proses penangkapan ikan

Tabel 3. Penyuluh Perikanan di Kecamatan Air Rami

\begin{tabular}{|c|c|c|}
\hline Nama & Jabatan & Pendidikan \\
\hline Eki Candra, S.Tr.Pi & PPB & DIV/S1 \\
\hline
\end{tabular}

Sumber : Data Sekunder 2019

dengan teknologi sederhana. Peraturan Menteri Kelautan dan Perikanan No. 2/PERMEN-KP/2015 Pada Pasal 2, jenis alat tangkap yang banyak digunakan oleh nelayan yang berada di kecamatan Air Rami yaitu Gill net, Tramel net, Jaring udang lobster, Left net, Fish net,
Pancing/Tonda, dan Pukat tradisional. Jenis ikan yang ditangkap yaitu ikan cakalang, tenggiri, ikan teri, layur, bawal dan udang lobster.

Grafik di atas menunjukkan bahwa puncak penangkapan ikan yaitu berada pada bulan September, Oktober, dan 
November sedangkan masa paceklik yaitu pada bulan Januari, Februari, Maret, dan April. Hasil tangkapan terbanyak pada tahun 2017 yaitu pada bulan Oktober sebanyak 22.066,40 kg, dan hasil tangkap terendah yaitu pada bulan Maret tahun 2017 sebanyak $2.187,60 \mathrm{~kg}$. Sedangkan pada tahun 2018 mengalami penurunan seperti yang dapat dilihat pada grafik diatas hasil penangkapan terbanyak yaitu pada bulan oktober $12.693,71 \mathrm{~kg}$ dan hasil tangkpan terendah pada bulan November 1.115,07 kg. Dapat disimpulkan dari data diatas hasil tangkapan nelayan Kecamatan Air Rami mengalami penurunan atau hasil tangkapan nelayan. Sebagian nelayan menjual hasil tangkapannya pada tengkulak, tidak di PPN setempat. Gambar 3 adalah nelayan Kecamatan Air Rami sedang menangkap ikan.

\section{Sistem Penyuluhan Perikanan}

Kelembagaan penyuluhan di Kecamatan Air Rami dikelola langsung oleh Dinas Kelautan dan Perikanan Kabupaten Mukomuko. Penyusunan programa dilakukan oleh tim penyuluh setiap kecamatan yang kemudian langsung diberikan kepada Dinas Kelautan dan Perikanan Kabupaten Mukomuko. Penyuluh Kecamatan Air Rami terdiri dari 1 penyuluh perikanan yaitu penyuluh perikanan bantu (PPB).
Kecamatan Air Rami mempunyai 1 orang penyuluh yaitu penyuluh perikanan bantu (PPB) dengan 12 desa daerah binaan. Diantaranya yaitu: Desa Air Rami, Desa Bukit Mulya, Desa Rami Mulya, Desa Talang Rio, Desa Arga Jaya, Desa Tirta Kencana, Desa Dusun Pulau, Desa Marga Mulya, Desa Cinta Asih, Desa Bukit Harapan, Desa makmur Jaya, dan Desa Mekar Jaya.

Sasaran utama kegiatan penyuluhan perikanan di Kecamatan Air Rami yaitu pelaku utama perikanan penangkapan ikan. Sasaran penyuluhan terdapat di dua desa sasaran yaitu Desa Air Rami dan Desa Talang Rio (UU No. 16 Tahun 2006 Tentang SP3K).

\section{Pembahasan}

Kondisi wilayah perikanan Kecamatan Air Rami

Wilayah Kecamatan Air Rami sebagian besar terletak pada perbukitan dengan ketinggian wilayah antara 5-700 meter di atas permukaan laut (dpl). Sebagian besar desa di Kecamatan Air Rami merupakan desa bukan pesisir yang jumlahnya mencapai 11 desa, sedangkan desa pesisir hanya satu desa yaitu Desa Air Rami. Suhu udara rata rata di Kecamatan Air Rami tertinggi mencapai $30^{\circ} \mathrm{C}$ terjadi pada bulan Agustus - September dan terendah 24,7음 C terjadi pada bulan Oktober - Maret. Curah hujan tertinggi terjadi pada bulan Januari yang mencapai ketinggian 
2.915,00 $\mathrm{mm}$ dan termasuk wilayah tropis (Badan Pusat Statistik 2018).

Curah hujan di Indonesia sangat bervariasi secara spasial dan temporal. Siklus tahunan dan setengah tahunan di dalam pola musiman curah hujan di Indonesia. Curah hujan di berbagai wilayah Indonesia berdasarkan tiga tipe hujan, yakni monsunal, ekuatorial, dan lokal. Hingga kini pembagian ini juga dianut oleh Badan Meteorologi Klimatologi dan Geofisika (BMKG) (Perdana 2015). Cuaca berupa dummy hujan dan dummy tinggi gelombang, sangat menentukan banyak dan tidaknya hasil tangkapan, karena pengaruh angin yang terlalu besar biasanya membuat takut para nelayan saat melakukan penangkapan ikan, sehingga kerja nelayan tidak maksimal (Azizi, Putri, dan Fahrudin 2017).

Kondisi potensi sumberdaya manusia perikanan

Sebagian nelayan tergabung dalam kelompok. Tidak semua nelayan tergabung dalam kelompok dapat terjadi karena ketidaktahuan nelayan atas manfaat peran kelompok dalam kehidupan perekonomian nelayan. Kondisi pelaku uatama perikana yang tidak tergabung dalam kelompok perikanan ini merupakan suatu masalah perikanan (Putri et al. 2019). Kelompok ini masih dalam kelas kelompok Pemula. Peningkatan kelas kelompok dapat dilakukan menggunakan strategi seperti peningkatan kedinamisan dan partisipasi anggota serta secara tidak langsung oleh peran pemimpin, kapasitas anggota, peran penyuluh, dukungan pihak luar, dan karakteristik anggota kelompok (Saepudin Ruhimat 2017). Kelompok nelayan bermanfaat bagi para anggotanya yaitu dapat meningkatkan pengetahuan-keterampilan, akses terhadap sumber-sumber produktif dan informasi terkait dengan modal, pasar, teknologi dan jaringan. Manfaat lanjut keberadaan kelompok nelayan adalah peningkatan produktivitas usaha perikanan (Rakhmanda et al. 2018).

Kelompok-kelompok nelayan mempunyai peranan penting dalam kehidupan sosial masyarakat. Kelompok nelayan sebagai wadah untuk mendapatkan akses daya dukung alat bagi masyarakat, sebagai media untuk beraktualisasi diri, sebagai wadah untuk mencapai segala tujuan yang diharapkan oleh warga masyarakat, sebagai media untuk memperoleh akses kekuaasaan terhadap pemerintah dan perusahan. Kelompok berproses dan berdinamika untuk mencapai tujuan mereka masingmasing (Khoeril Mala 2016). Nazaruddin Margolang (2018) menjelaskan keberadaan kelompok saat ini memiliki kecenderungan statis bahkan menurun kuantitas dan kualitasnya. Kondisi kelompok berkaitan dengan kinerja 
penyuluh. Peningkatan kelas kemampuan kelompok dilakukan melalui peningkatan kinerja penyuluhan dan pemberdayaan petani dalam kelompoknya.

\section{Sistem produksi perikanan tangkap}

Hasil tangkapan nelayan berubaberupah pada setiap bulannya. Hasil tangkapan nelayan juga menurun pada tahun 2017-2018. Penurunan hasil tangkapan mengakibatkan penurunan pendapatan nelayan. Fatullah and Harudu (2019) mengungkapkan bahwa faktor-faktor yang mempengaruhi pendapatan nelayan antara lain cuaca dan musim adalah faktor yang paling dominan.

Masyarakat nelayan mengalami hambatan dalam melakukan kegiatan penangkapan ikan. Hambatan dalam menghadapi kemajuan IPTEK disebabkan oleh faktor alam, faktor modal, kenaikan BBM, pengoprsian alat tangkap, sulitnya mendapatkan bahan maupun peralatan melaut dan kurangnya pengetahuan. Strategi adaptasi yang dapat dilakukan untuk mengatasi permasalahan tersebut antara lain perlu penganekaragaman alat tangkap ikan, pembuatan peralatan mandiri, penganekaragaman pekerjaan, peranan lembaga sosial berupa Koperasi, bantuan dari pemerintah dan adanya sistem sewa. Masyarakat nelayan perlu memiliki penguasaan aspek informasi dalam hal cuaca, lokasi ikan dan teknologi. Peran pemerintah yang dapat dilakukan adalah kerjasama antara Kementerian Kelautan dan Perikanan dengan Badan Meteorologi dan Geofisika (BMG) mengenai kondisi cuaca berdasarkan informasi pemanfaatan teknologi, sehingga nelayan dapat memprediksi cuaca (Jannah 2016).

Ketidakpastian hasil tangkapan dan sistem pemasarannya yang tidak optimal membuat nelayan kesulitan dalam permodalan melaut. Nelayan mencari modal melalui proses yang cepat dan tanpa agunan kepada tengkulak/pengijon. yang pada kondisi tertentu telah menciptakan sistem monopoli karena mereka juga menyediakan modal, faktor-faktor produksi sampai menentukan pemasaran ikan. Kasus di PPN Palabuhanratu menjelaskan bahwa nelayan memanfaatkan tengkulak untuk memperoleh permodalan melaut. Hal ini dikarenakan proses peminjamannya lebih mudah dan tanpa agunan. Kekurangan sistem tengkulak adalah sebagian besar hasil tangkapan harus dijual pada tengkulak tanpa melalui pelelangan, mengakibatkan nelayan mengalami keregian. Kerugian lain adalah pembelian pembelian abhan bakar melalui tengkulak lebih tinggi dari 
harga SPBU (nelayan pancing dan gillnet). Peneliti menyarankan peranan pelabuhan perikanan (PPN) perlu dioptimalkan dalam mengupayakan penyediaan perbekalan melaut dan terlaksananya sistem pelelangan ikan secara menyeluruh agar nelayan kecil memiliki posisi tawar dalam tata niaga perikanan dan mendapatkan hasil penjualan secara cash (Lubis et al. 2012).

\section{Sistem penyuluhan perikanan}

Sistem Penyuluhan Perikanan Percakapan tentang Sistem Penyuluhan, selama ini belum banyak dilakukan, bahkan istilah Sistem Penyuluhan itu sendiri nampaknya baru mulai banyak disebut oleh banyak kalangan sejak ditetapkannya Undang-Undang No.16 Tahun 2006. Tentang Sistem Penyuluhan Pertanian, Perikanan, dan Kehutanan. Dalam undang-undang tersebut, pengertian sistem penyuluhan mencakup : kebijakan, kelembagaan, ketenagaan, penyelenggaraan, pembiayaan, pengawasan dan pengendalian penyuluhan (Mardikanto 2014).

Peran penyuluh perikanan sangat besar dalam meningkatkan kapasitas pelaku perikanan seperti nelayan. Penyuluh perikanan mempunyai peranan dari penyampaian informasi perikanan, penyaluran sarana produksi perikanan serta peran penyuluh perikanan dalam proses pengolahan dan pemasaran hasil. Keberhasilan penyuluhan merupakan sinergi antara kemampuan penyuluh dalam menyampaikan informasi dan inovasi serta peranan masyarakat baik nelayan atau petambak yang mempunyai minat yang tinggi mengikuti dan mencoba menerapkan inovasi. Kegiatan penyuluhan sangat efektif dalam pegembangan sektor perikanan sehingga dapat meningkatkan kemampuan nelayan dan petani tambak menerapkan inovasi pada kegiatan perikanannya (Safrida, Makmur, dan Fachri 2015).

\section{SIMPULAN DAN SARAN}

\section{Simpulan}

Luas wilayah Kecamatan Air Rami $\pm 99,20$ km² $^{2}$ serta jumlah RTP sebanyak 120 RTP dibidang penangkapan. Kondisi wilayah Kecamatan Air Rami adalah salah satu Kecamatan yang memiliki potensi cukup baik dalam bidang perikanan di Kabupaten Mukomuko. Sistem produksi penangkapan ikan di Kecamatan Air Rami menggunakan jenis alat tangkap Left Net, fish Net, Pancing/Tonda, dan Pukat Tradisional. Kegiatan penyuluhan perikanan berjalan berdasarkan aspirasi dari masyarakat, di Kecamtan Air Rami hanya memiliki satu orang penyuluh yaitu Eki Candra, S.Tr.Pi, peran penyuluh sangat penting 
bagi masyarakat guna meningkatkan kelompok perikanan.

\section{Saran}

Berdasarkan kesimpulan diatas maka penulis menyarankan perlunya kegiatan pemberdayaan masyarakat terutama pada pelaku utama perikanan agar dapat meningkatkan kinerja kelompok dan cara penanganan mutu ikan. Adanya kesadaran nelayan untuk berkembang lebih baik dan membuat pemikiran bahwa kelompok yang mereka bentuk bersama-sama harus berjalan sebagai mana fungsi kelompok semestinya. Pendampingan penyuluh terhadap kelompok perikanan mengenai fungsi dan peran kelompok perikanan secara terpadu dan berkelanjutan agar dapat meningkatkan kapasitas diri nelayan.

\section{DAFTAR PUSTAKA}

Azizi, Eka Intan Kumala Putri, dan Achmad Fahrudin. 2017. "Analisis Faktor-Faktor yang Mempengaruhi Perubahan (Kasus: Desa Muara Kecamatan Blanakan Kabupaten Subang)." Jurnal Sosek Kelautan dan Perikanan 12(2):225-33.

Badan Pusat Statistik. 2018. Kecamatan Air Rami dalam Angka. 1 ed. Mukomuko: BPS Kabupaten Mukomuko.
Fatullah, Sofian, dan La Harudu. 2019. “Deskripsi faktor-faktor yang mempengaruhi penghasilan perikanan di desa koholifano, kecamatan pasir putih kabupaten muna." Jurnal Penelitian Pendidikan Geografi. 4(4):221-25. Hendrik. 2010. "Potensi Sumberdaya Perikanan dan Tingkat Eksploitasi (Kajian terhadap Danau Pulau Besar dan Danau Bawah Zamrud Kabupaten Siak Provinsi Riau)." Jurnal Perikanan dan Kelautan 15(2):121-31.

Jannah, Miftakhul. 2016. "Strategi Adaptasi Masyarakat Nelayan Dalam Menghadapi Kemajuan IImu Pengetahuan dan Teknologi (Studi Kasus Nelayan Desa Jetis Kecamatan Nusawungu Kabupaten Cilacap)." Universitas Negeri Semarang.

Khoeril Mala, Syipah. 2016. "Peran dan Dinamika Kelompok Dalam Kehidupan Sosial Ekonomi Nelayan (Studi Kasus di Desa Citemu Kecamatan Mundu Kabupaten Cirebon)." Orasi 7(1):1-20. doi: 10.24235/orasi.v7i1.1003.

Kusnandar, dan Sri Mulyani. 2015. "Strategi Pengelolaan Sumberdaya Perikanan Berbasis Ekosistem." OSEATEK 9(01):9-20. 
Lubis, Ernani, Anwar Bey Pane, Retno Muninggar, dan Asep Hamzah. 2012. "Besaran Kerugian Nelayan dalam Pemasaran Hasil Tangkapan: Kasus Pelabuhan Perikanan Nusantara

Palabuhanratu." Maspari Jurnal 4(2):159-67.

Mahfrudin, Zainal Rosyid, Tatty Yuniarti, dan Toni Ruchimat. 2020. "Kajian Potensi Sumberdaya Perikanan Di Kecamatan Sanden Kabupaten Bantul Provinsi Daerah Istimewa Yogyakarta." Marlin 1(1):47-56.

Mardikanto, Totok. 2014. Sistem Penyuluhan Pertanian. Surakarta: UNS Press.

Margolang, Nazaruddin. 2018. "Strategi Peningkatan Kelas Kemampuan Kelompok Tani." Jurnal Agro Riau 1(3):1-18. doi:

10.31227/osf.io/4xmev.

Perdana, Tito Aditya. 2015. "Dampak Perubahan Iklim Terhadap Nelayan Tangkap (Studi Empiris di Pesisir Utara Kota Semarang) [Skripsi]." Universitas Diponegoro.
Putri, Jasmine Addinda, Tatty Yuniarti, Ita Junita, dan Puspa Dewi. 2019. "Analisis Permasalahan Perikanan: Strategi Penyuluhan Perikanan di Kecamatan Cigasong Kabupaten Majalengka [ Analysis of Fisheries Extension Problems in Cigasog District , Majalengka Regency ]." Jurnal Penyuluhan Perikanan dan Kelautan 13(2):149-68.

Saepudin Ruhimat, Idin. 2017. "Peningkatan Kapasitas Kelembagaan Kelompok Tani dalam Pengembangan Usahatani Agroforestry : Studi Kasus di Desa Cukangkawung, Kecamatan Sodonghilir, Kabupaten Tasikmalaya, Provinsi Jawa Barat." Jurnal Penelitian Sosial dan Ekonomi Kehutanan 14(1):1-17. doi: 10.20886/jsek.2017.14.1.1-17.

Safrida, T. Makmur, dan Hafid Fachri. 2015. "Peran Penyuluh Perikanan Dalam Pengembangan Sektor Perikanan Di Kabupaten Aceh Utara." Agrisep 16(2):17-27.

Sumarsono, Drs Sonny. 2003. Ekonomi Manajemen Sumberdaya Manusia dan Ketenagakerjaan. 1 ed. Yogyakarta (ID): Graha IImu. 